\title{
Pengaruh Stimulus Kutaneus Slow-Stroke Back Massage Terhadap Skala Nyeri Dismenore Primer Pada Mahasiswi Stikes Amanah di Padang
}

\author{
Vetty Priscilla $^{a}$, Esi Afriyanti ${ }^{a}$ \\ aBagian Keperawatan Meternitas dan Anak, Fakultas Keperawatan Universitas Andalas, Padang, \\ 25163, Indonesia \\ ${ }^{\mathrm{b} B a g i a n}$ Keperawatan Medikal Bedah - Keperawatan Gawat Darurat Fakultas Keperawatan \\ Universitas Andalas, 25163, Indonesia \\ e-mail : vettypriscilla@gmail.com
}

\begin{abstract}
Puberty in girls is indicated by a menstruation. Each adolescent girls have a different experience of their periods. Some girls get period without any complaints, but some of them accompanied with dysmenorrhea which resulted in a sense of discomfort in the form of pain that can interfere their daily activities. According to AHCPR (Agency for Health Care Policy and Research), pain management that can be performed by nurses are nonpharmacological therapy, one of which is cutaneous stimulation, Slow-Stroke Back Massage. This study aimed to investigate the direct effect of cutaneous stimulus: Slow-Stroke Back Massage on primary dysmenorrhea pain scale. Design for this reasearc is a quasi experiment in one group (one group pre test-post test design). Subjects in this study were 12 female nursing students of Stikes Amanah Padang who have met criteria of the study. Subjects had been taught about technique of slow-stroke back message, and practice during their period when dysmenorrhea felt for 1 week. Previously, pain experience during menstruation assessed using a scale Numerical Rating Scales (NRS). Data were analyzed using paired t-test. This study showed that more than half of female students (75\%) were experienced a moderate level of dysmenorrhea pain with pain scale was $5.67 \pm 1.56$ before being given cutaneous stimulus slow-stroke back massage (pretest). After given the slowstroke back message (posttest), more than half (58.2\%) experienced a mild level of pain dysmenorrhea with pain scale was $4 \pm 2.09$. The cutaneous stimulus slow-stroke back message can reduce dysmenorrhea pain scale of nursing students in STIKes Amanah Padang.
\end{abstract}

Keywords: $\quad$ Cutaneous Stimulus Slow-Stroke Back Message, Dysmenorrhea Pain, Nursing Students

\begin{abstract}
Abstrak
Masa remaja pada remaja putri salah satunya ditandai dengan datangnya menstruasi. Menstruasi yang dialami memiliki pengalaman yang berbeda-beda. Sebagian remaja mendapatkan menstruasi tanpa keluhan, namun beberapa dari mereka disertai keluhan berupa dismenore yang mengakibatkan rasa ketidaknyamanan berupa nyeri yang pada akhirnya berdampak terhadap gangguan aktivitas remaja. Menurut AHCPR (Agency for Health Care Policy and Research) penatalaksanaan nyeri yang dapat dilakukan perawat adalah terapi nonfarmakologi, salah satunya adalah stimulasi kutaneus Slow-stroke Back Massage. Penelitian ini bertujuan untuk meneliti efek langsung pengaruh Stimulus Kutaneus Slow-Stroke Back Massage Terhadap Skala Nyeri Dismenore Primer. Penelitian ini menggunakan Quasi Eksperimen dalam satu kelompok (one group pre test - post test design). Subjek dalam penelitian ini adalah 12 orang mahasiswi Stikes Amanah Padang yang telah memenuhi kriteria penelitian. Subjek diajarkan teknik stimulus slow-stroke back message, dan mempraktekkannya selama haid ketika rasa nyeri haid menyerang selama 1 minggu. Sebelumnya dikaji pengalaman nyeri menstruasi mahasiswi sebelumnya dengan menggunakan skala Numerical Rating Scales (NRS). Data dianalisa dengan menggunakan paired $\mathrm{t}$-test. Sebelum diberikan stimulus kutaneus slow-stroke back message (pretest). Penelitian ini memperlihatkan lebih dari separuh mahasiswi (75\%) mahasiswi mengalami tingkat nyeri dismenore sedang dengan skala nyeri 5,67 $\pm 1,56$. Setelah diberikan stimulus slow-stroke back message (posttest) lebih dari separuh $(58,2 \%)$ mahasiswi mengalami tingkat nyeri dismenore ringan dengan skala nyeri $4 \pm 2,09$. Kesimpulan
\end{abstract}


NERS: Jurnal Keperawatan, Volume 13, No. 2, Oktober 2017, (Hal. 96-104)

dari penelitian ini adalah stimulus kutaneus slow-stroke back message dapat menurunkan skala nyeri dismenore pada mahasiswi Stikes amanah Padang.

Kata kunci : Stimulus Kutaneus Slow-Stroke Back Message, Nyeri Dismenore, Mahasiswa Keperawata 


\section{PENDAHULUAN}

Masa remaja adalah masa transisi dari masa kanak-kanak menuju masa dewasa. Menurut Monks (2002) masa remaja merupakan suatu fase perkembangan yang dinamis dalam kehidupan seseorang. Masa ini merupakan periode transisi dari masa anak ke masa dewasa yang ditandai dengan percepatan perkembangan fisik, mental, emosional, dan sosial. Masa remaja ditandai dengan munculnya karakteristik seks primer. Hal ini sangat dipengaruhi oleh mulai bekerjanya kelenjar reproduksi. Fase perkembangan ini ditandai dengan pengalaman mimpi basah pada remaja putra dan mengalami menstruasi pada remaja putri (Chomaria, 2008). Menstruasi adalah keluarnya darah dari rahim melalui vagina dan keluar dari tubuh seorang wanita setiap bulan selama masa usia subur (Faizah, 2000).

Keadaan yang sering ditakuti oleh remaja putri pertama kali adalah menstruasi pertama, atau dalam bahasa medis disebut dengan menarche. Kejadian ini menandakan seorang remaja putri telah memasuki masa pubertas (Riyanto, 2001). Kejadian yang penting dalam pubertas adalah pertumbuhan badan yang cepat, timbulnya ciri-ciri kelamin sekunder, menarche, dan perubahan psikis (Sastrawinata, 2008).

Wanita yang mengalami menstruasi memiliki pengalaman yang berbeda-beda. Sebagian wanita mendapatkan menstruasi tanpa keluhan, namun beberapa dari mereka yang mendapatkan menstruasi disertai keluhan berupa dismenore yang mengakibatkan rasa ketidaknyamanan yang pada akhirnya berdampak terhadap gangguan aktivitas. Dismenore merupakan nyeri perut bagian bawah yang terkadang rasa nyeri tersebut meluas hingga ke pinggang, punggung bagian bawah dan paha (Baziad, 2003).
Dismenore terjadi karena peningkatan prostaglandin (PG) F2-alfa yang merupakan suatu siklooksigenase (COX-2) yang mengakibatkan hipertonus dan vasokonstriksi pada miometrium sehingga terjadi iskemia dan nyeri haid. Selain itu juga terdapat PGE2 alfa yang turut serta menyebabkan dismenore primer (Hillard, 2006). Dismenore yang sering terjadi pada remaja adalah dismenore primer. Dismenore primer adalah suatu nyeri haid yang tidak terdapat hubungan dengan kelainan ginekologik (Simanjuntak, 2008). Remaja putri akan lebih sering merasakan sakit akibat dismenore primer karena siklus hormonal yang dialami belum begitu stabil, dan remaja putri belum sering mengalami kontraksi uterus seperti wanita dewasa muda. Dismenore primer ini akan sangat mengganggu konsentrasi dan aktivitas para remaja putri (Junizar, Sulianingsih \& Widya, 2001).

Nyeri haid / dismenore merupakan ketidakseimbangan hormon progesteron dalam darah sehingga mengakibatkan rasa nyeri timbul, faktor psikologis juga ikut berperan terjadinya dismenore pada beberapa wanita. Wanita yang pernah mengalami dismenore sebanyak $90 \%$. Masalah ini setidaknya mengganggu 50\% wanita masa reproduksi dan $60-85 \%$ pada usia remaja, yang mengakibatkan banyaknya absensi pada sekolah maupun kantor. Pada umumnya 50-60\% wanita diantaranya memerlukan obat-obatan analgesik untuk mengatasi masalah dismenore ini (Anna, 2009).

Bentuk nyeri haid yang banyak dialami oleh remaja adalah kekakuan atau kejang dibagian bawah perut. Rasanya sangat tidak menyenangkan sehingga menyebabkan mudah marah, gampang tersinggung, mual, muntah, berat badan naik, perut kembung, punggung terasa nyeri, sakit kepala, timbul jerawat, tegang, lesu, dan depresi. Biasanya gejala ini 
datang sehari sebelum masa menstruasi dan berlangsung selama 2 hari sampai berakhirnya masa menstruasi (Dianawati, 2003).

Nyeri haid terjadi pada lebih dari setengah wanita usia reproduksi dengan prevalensi yang beragam. Hampir 2/3 remaja postmenarche di Amerika Serikat mengalami nyeri haid dan lebih dari $10 \%$ dari mereka begitu menderita sehingga tidak bisa masuk sekolah, sehingga nyeri haid merupakan penyebab utama absensi pada remaja wanita (Dito, 2008). Menurut penelitian, frekuensi dismenore cukup tinggi hampir $90 \%$ wanita mengalami dismenore, $10-15 \%$ diantaranya mengalami dismenore berat yang menyebabkan mereka tidak mampu melakukan kegiatan apapun dan ini menurunkan kualitas hidupnya (Anna, 2009).

Menurut beberapa laporan internasional prevalensi dismenore sangat tinggi dan setidaknya $50 \%$ remaja putri mengalami dismenore sepanjang tahun reproduktif. Studi epidemiologi di Swedia juga melaporkan angka prevalensi nyeri menstruasi sebesar $80 \%$ remaja usia 19-21 tahun mengalami nyeri menstruasi, $15 \%$ membatasi aktivitas harian ketika menstruasi dan membutuhkan obat-obatan penangkal nyeri, 8-10\% tidak mengikuti atau masuk sekolah dan hampir $40 \%$ memerlukan pengobatan medis. Keadaan ini disisi pendidikan maupun finansial dan kualitas hidup perempuan tidak baik (Widjanarko, 2007). Angka kejadian nyeri menstruasi primer di Indonesia mencapai $54,89 \%$, sedangkan sisanya adalah penderita tipe sekunder, yang menyebabkan mereka tidak mampu melakukan kegiatan apapun dan ini akan menurunkan kualitas hidup pada individu masing-masing (Proverawati \& Misaroh, 2009).

Nyeri menstruasi terjadi karena pelepasan prostaglandin (PG) F2-alfa, yang merupakan suatu siklooksigenasi (COX) yang dapat mengakibatkan hipertonus dan vasokonstriksi pada miometrium sehingga terjadi iskemi. Dan juga terdapat PGE-2 yang turut serta menyebabkan dismenore primer. Dimana peningkatan level PGF2alfa dan PGE-2 jelas akan meningkatkan rasa nyeri pada saat menstruasi (Hillard, 2006).

Ada beberapa cara untuk meredakan gejala-gejala dismenore yaitu dengan cara farmakologi dan non farmakologi. Pengobatan yang dapat dipakai adalah dengan menggunakan agenagen anti inflamasi nonsteroid (NSAID) yang bekerja sebagai antiprostaglandin yang dapat meredakan nyeri. Obat farmakologi yang sering digunakan adalah analgesik dan anti inflamasi seperti asam mefenamat, ibuprofen, dan lain-lain. Akan tetapi penggunaan obat farmakologis menimbulkan efek samping seperti gangguan pada lambung dan penurunan pada darah (anemia).

Pedoman AHCPR (Agency for Health Care Policy and Research) untuk penatalaksanaan nyeri menyebutkan bahwa intervensi nonfarmakologis merupakan intervensi yang cocok untuk pasien yang tidak ingin menggunakan terapi obat dalam mengatasi nyerinya dan pasien yang merasa cemas karena masih merasakan nyeri setelah menggunakan terapi farmakologi. Stimulasi kutaneus, distraksi, relaksasi, bimbingan antipasi, biofeedback dan hipnosis adalah contoh intervensi nonfarmakologis yang sering digunakan dalam keperawatan dalam mengelola nyeri (Potter \& Perry, 2005).

Stimulus kutaneus: slow-stroke back massage adalah stimulasi kulit yang dilakukan untuk menurunkan intensitas nyeri sedang, bekerja dengan cara mendorong pelepasan endorfin, sehingga memblok transmisi stimulus nyeri. Cara lainnya adalah dengan mengaktifkan transmisi serabut saraf sensori A-beta yang lebih besar dan lebih cepat, sehingga menurunkan transmisi nyeri melalui serabut $\mathrm{C}$ dan A-delta berdiameter kecil sekaligus menutup gerbang sinap untuk 
transmisi impuls nyeri. Teknik untuk stimulasi kutaneus slow-stroke back massage dilakukan dengan metode mengusap kulit klien secara berlahan dan berirama selama \pm 10 menit (Potter \& Perry, 2005).

Penggunaan stimulus kutaneus: SSBM yang benar dapat mengurangi persepsi nyeri dan membantu mengurangi ketegangan otot yang dapat menurunkan intensitas nyeri, disamping itu juga dapat menimbulkan pelebaran pembuluh darah dan memperbaiki peredaran darah di dalam jaringan tersebut. Dengan cara ini penyaluran zat asam dan bahan makanan ke sel-sel diperbesar dan pembuangan dari zat-zat yang tidak terpakai akan diperbaiki. Jadi akan timbul proses pertukaran zat yang lebih baik. Aktifitas sel yang meningkat akan mengurangi rasa nyeri dan meningkatkan relaksasi fisik dan psikologis (Kusyati, 2006).

Tehnik ini sederhana dan mudah dilakukan, sehingga setiap perawat dan institusi kesehatan bisa menerapkannya untuk mengatasi masalah nyeri, khususnya pada nyeri dismenore. Tindakan ini juga memungkinkan perawat untuk memeriksa kondisi kulit pasien (Ester, 2005). Keuntungan dari stimulus kutaneus slowstroke back massage (SSBM) adalah tindakan ini dapat dilakukan di rumah, sehingga memungkinkan pasien dan keluarga melakukan upaya dalam mengontrol nyeri (Potter \& Perry, 2005).

Stimulus kutaneus slow-stroke back massage dapat membantu kemandirian klien dan keluarga dalam mengelola nyeri, khususnya bagi pasien yang sulit mendapatkan fasilitas pelayanan medis atau pasien yang tidak ingin mengatasi nyeri dengan menggunakan terapi farmakologis. Selain itu dalam pemberian stimulus kutaneus slow-stroke back massage (SSBM) menggunakan teknik yang sederhana dan tidak perlu menggunakan alat khusus yang membutuhkan biaya yang besar sehingga stimulus ini dapat diberikan kepada masyarakat mulai dengan tingkat ekonomi atas hingga masyarakat ekonomi bawah.

Dengan kondisi seperti di atas, maka sebagai seorang perawat perlu mengetahui tentang tehnik stimulus kutaneus slow-stroke back massage dan efeknya yang dapat memberikan rasa nyaman bagi penderita nyeri. Hal ini berguna untuk membantu perawat meningkatkan pelayanannya dalam mengurangi rasa cemas dan nyeri yang dirasakan oleh penderita nyeri, karena rasa nyeri tersebut mengganggu aktivitas penderita untuk memenuhi kebutuhan hidup mereka sehari-hari.

Beberapa penelitian juga telah mengidentifikasi pengaruh dari slowstroke back massage ini. Salah satunya adalah penurunan kecemasan dan intensitas nyeri bahu pada lansia yang dirawat di rumah sakit dengan stroke serta perubahan positif pada denyut jantung dan tekanan darah, yang mengindikasikan relaksasi pada lansia (Mok E \& Woo CP, 2004). Begitu juga hasil penelitian yang dilakukan Medical Shoker (2008), pemberian stimulus kutaneus: slow-stroke back massage berpengaruh terhadap intensitas nyeri osteoatritis pada lansia. Namun belum ada penelitian yang khusus menerapakan teknik ini pada nyeri dismenore.

Hasil survey pendahuluan bulan Desember 2013 terhadap 254 orang mahasiswi di Program Studi Ilmu Keperawatan Stikes Amanah Padang didapatkan jumlah mahasiswi yang mengalami nyeri menstruasi sebanyak 98 orang dengan 56 orang $(57,14 \%)$ orang mengalami nyeri ringan, $16(16,32 \%)$ orang nyeri sedang, dan $26(26,53 \%)$ orang mengalami nyeri berat sehingga biasanya mahasiswi-mahasiswi yang mengalami dismenore sering minta izin pulang dengan alasan mereka tidak sanggup mengikuti kegiatan belajar mengajar. Dampak dari absensi itu adalah mahasiswi itu sering mendapatkan tugas bahkan ada yang tidak dapat mengikuti ujian UAS 
karena tidak lengkapnya kehadiran. Upaya penanganan dismenore yang dilakukan oleh sebagian mahasiswi adalah dengan istirahat atau tidur di kamar sambil menekan bagian perut yang sakit dan mengoleskan minyak kayu putih pada daerah nyeri, bahkan ada yang hanya menahan nyeri nya saja sambil menangis.

Berdasarkan uraian diatas bahwa banyak dan beratnya konsekuensi akibat dismenore ini pada mahasiswi maka dibutuhkan terapi nonfarmakologis yang dapat dilakukan untuk mengurangi nyeri, maka peneliti tertarik untuk meneliti secara langsung tentang pengaruh Pengaruh Stimulus Kutaneus Slow-Stroke Back Massage Terhadap Skala Nyeri Dismenore Primer Pada Mahasiswi Keperawatan Stikes Amanah Padang.

\section{METODE}

Penelitian ini menggunakan Quasi Eksperimen dalam satu kelompok (one group pre test - post test design). Subjek dalam penelitian ini adalah 12 orang mahasiswi Tk I dan II Stikes Amanah Padang yang memenuhi kriteria sebagai berikut: Tidak mempunyai kontra indikasi utuk dilakukan istimulasi kutaneus: slowstoke back massage seperti: fraktur tulang, luka bakar/luka terbuka pada daerah punggung, daerah kemerahan pada daerah punggung, osteoporosis dan asam urat; bersedia dilakukan stimulasi kutaneus : slow- stroke back massage; Intensitas nyeri dismenore skala sedang dan berat; respoden yang mempunyai riwayat haid teratur 1 bulan terakhir, tidak mengkonsumsi obat pereda nyeri seperti analgesic, tidak menderita suatu penyakit atau kelainan reproduksi. Subjek diajarkan teknik stimulus slow-stroke back message, dan akan mempraktekkan selama haid ketika rasa nyeri haid menyerang selama 1 minggu tersebut. Data dianalisa dengan menggunakan paired t-test.

\section{HASIL}

Penelitian ini telah dilakukan di Stikes Amanah pada mahasiswi Tingkat I dan II pada Bulan Juli sampai November tahun 2014 dengan jumlah sampel sebanyak 12 mahasiswi. Dari kegiatan pengambilan data didapatkan sebagai berikut;

Berdasarkan tingkatan nyeri, maka dapat dilihat sebarannya sebagai berikut:

Tabel 1. Berdasarkan tingkatan nyeri, maka dapat dilihat sebarannya sebagai berikut:

\begin{tabular}{lccc} 
No. & $\begin{array}{c}\text { Tingkat } \\
\text { Nyeri }\end{array}$ & $\begin{array}{c}\text { Frekuensi } \\
(\mathbf{n})\end{array}$ & $\begin{array}{c}\text { Presentase } \\
(\boldsymbol{\%})\end{array}$ \\
\hline 1. & Ringan & 0 & 0 \\
\hline 2. & Sedang & 9 & 75 \\
\hline 3. & Berat & 3 & 25 \\
\hline & TOTAL & 12 & 100 \\
\hline
\end{tabular}

Pada tabel Dari tabel 1, dapat dilihat bahwa sebelum diberi perlakuan yaitu pijatan slow-stroke Back Message (pretest) yaitu terdapat 9 orang $(75 \%)$ mahasiswi Stikes Amanah Padang mengalami nyeri sedang, dibandingkan yang nyeri berat. Sedangkan yang menderita nyeri ringan tidak ada sama sekali.

Nyeri adalah alasan utama seseorang untuk mencari bantuan perawatan (Smeltzer \& Bare, 2002). Nyeri bersifat subjektif, tidak ada dua individu yang mengalami nyeri yang sama dan tidak ada dua kejadian nyeri yang sama menghasilkan respon atau perasaan yang identik pada seorang individu (Potter \& Perry, 2006). Nyeri haid (dismenore) merupakan nyeri yang diakibatkan karena terjadi kontraksi otot rahim akibat

peningkatan prostaglandin sehingga menyebabkan vasospasme dari arteriol uterin yang menyebabkan terjadinya iskemia dan kram pada abdomen bagian bawah yang akan merangsang rasa nyeri di saat datang bulan (Robert dan David, 
2004). Dismenore yang sedemikian hebatnya memaksa penderita untuk istirahat dan meninggalkan pekerjaan atau cara hidupnya sehari-hari, untuk beberapa jam atau beberapa hari (Simanjuntak, 2008).

Berdasarkan hasil pengambilan data menggunakan skala nyeri mankoski, dari 12 orang mahasiswi yang mengalami dismenore yaitu nyeri sedang dan berat. Melalui tingkatan dari skala nyeri mankoski tersebut terdapat gangguan terhadap aktivitas pada siswi dalam proses belajar yang membutuhkan konsentrasi, tidur untuk beristirahat, serta aktivitas lainnya. Hasil penelitian ini juga sesuai dengan penelitian, Tangchai (2004), dismenore menyebabkan gangguan aktivitas sehari-hari dan harus absen dari sekolah 1-7 hari setiap bulannya pada $15 \%$ responden berusia $15-17$ tahun. Remaja dengan dismenore berat mendapat nilai yang rendah $(6,5 \%)$, menurunya konsentrasi $(87,1 \%)$ dan absen dari sekolah $(80,6 \%)$. Dimana lebih dari $60 \%$ wanita dismenore melaporkan bahwa konsentrasi belajar mereka dipengaruhi oleh nyeri ini.
Tabel 2. Gambaran Tingkat Nyeri Dismenore Setelah diberikan Slow-stroke Back Massage Pada Mahasiswi Stikes Amanah Padang Tahun 2014

\begin{tabular}{lccc} 
No. & $\begin{array}{c}\text { Tingkat } \\
\text { Nyeri }\end{array}$ & $\begin{array}{c}\text { Frekuensi } \\
(\mathbf{n})\end{array}$ & $\begin{array}{c}\text { Presentase } \\
(\boldsymbol{\%})\end{array}$ \\
\hline 1. & Ringan & 7 & 58,2 \\
\hline 2. & Sedang & 3 & 25,0 \\
\hline 3. & Berat & 2 & 16,7 \\
\hline & TOTAL & 12 & 100,0 \\
\hline
\end{tabular}

Dari tabel 2 diatas menunjukkan bahwa setelah diberikan perlakuan (post-test), terdapat 7 orang $(58,2 \%)$ mahasiswi stikes Amanah Padang mengalami nyeri ringan.

\begin{abstract}
Analisa Bivariat
Pada analisa bivariat ini menggunakan data numerik untuk melihat perubahan nyeri dismenore pada mahasiswi akibat pemberian Slow-stroke Back Massage
\end{abstract}

Tabel 3. Pengaruh Stimulus Kutaneus Slow Stroke Back Massage Terhadap Skala Nyeri pada mahasiswi Stikes Amanah Padang tahun 2014

\begin{tabular}{|c|c|c|c|c|c|c|}
\hline \multirow{3}{*}{ Intensitas nyeri } & \multicolumn{4}{|c|}{ 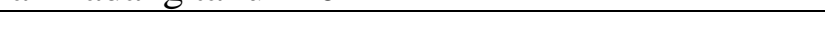 } & \multirow{3}{*}{$\mathrm{T}$} & \multirow{3}{*}{$\mathrm{P}$} \\
\hline & \multirow{2}{*}{ mean } & \multirow{2}{*}{$\begin{array}{c}\text { Std. } \\
\text { deviasi }\end{array}$} & \multicolumn{2}{|c|}{$95 \%$ confidence interval } & & \\
\hline & & & Lower & Upper & & \\
\hline $\begin{array}{l}\text { Pretest - post } \\
\text { test }\end{array}$ & 1,67 & 1,44 & 0,75 & 2,58 & 4,02 & 0,002 \\
\hline
\end{tabular}

Dari tabel 3 diatas, diketahui bahwa setelah dilakukan uji paired $t$ - test dengan derajat kepercayaan sebesar $95 \%$ didapatkan nilai $\mathrm{p}=0,002(\mathrm{p}<0,05)$ yang artinya secara statistik terdapat penurunan bermakna tingkat nyeri haid (dismenore ) setelah pemberian intervensi.

Dari tabel 5 diatas menunjukkan bahwa setelah diberikan perlakuan (posttest), terdapat 7 orang $(58,2 \%)$ mahasiswi stikes Amanah Padang mengalami nyeri ringan, berarti telah terjadi penurunan dari skala nyerinya. Hal ini juga diperkuat dengan uji paired t-test yang menunjukkan bahwa penurunan skala nyeri dismenore pada mahasiswa bermakna, yang berarti stimulus slow-stroke back message dapat menurunkan skala nyeri dismenore mahasiswa stikes Amanah Padang.

Sesuai dengan Gate Control Theory bahwa Stimulus kutaneus dapat menurunkan nyeri, bekerja dengan cara mendorong pelepasan endorfin, sehingga memblok transmisi stimulus nyeri. Cara 
lainnya adalah dengan mengaktifkan transmisi serabut saraf sensori A-beta yaitu serat saraf bermielin yang besar sehingga mengantarkan impuls ke sistem saraf pusat jauh lebih cepat dan lebih besar dari pada serabut A delta atau serabut $C$ yang, sehingga menurunkan transmisi nyeri melalui serabut $\mathrm{C}$ dan A-delta berdiameter kecil sekaligus menutup gerbang sinap untuk transmisi impuls nyeri (Potter \& Perry, 2005).

Sesuai dengan penelitian yang dilakukan oleh Richard (2011), pasien yang menderita nyeri punggung yang mendapatkan massase dengan pijat akan lebih sedikit menggunakan obat penghilang nyeri dan beraktivitas lebih baik. Begitu juga dengan penelitan yang dilakukan Mok E \& Woo CP (2004), adanya penurunan kecemasan dan intensitas nyeri bahu pada lansia yang di rawat di rumah sakit dengan stroke serta perubahan positif pada denyut jantung dan tekanan darah, yang mengindikasikan relaksasi pada lansia yang diberikan stimulus kutaneus slow back stroke massage.

Setelah dilakukan stimulasi kutaneus slow stoke back massage, 10 dari 12 mahasiswi mengalami penurunan skala nyeri dan 2 mahasiswi lagi skala nyerinya tidak mengalami penurunan yaitu skala nyeri pretest dan posttest sama.

Pada penelitian ini, setelah diberikan stimulus kutaneus slow stroke back massage pada responden masih terdapat skala nyeri 9 dan skala 7 . Individu mengekspresikan nyeri berbeda-beda tergantung pada faktor-faktor yang mempegaruhi nyeri yaitu faktor psikologis, kognitif berintekrasi, dan faktor neurofisiologis disamping itu juga faktor pengalaman masa lalu terhadap nyeri, usia, budaya, ansietas, makna nyeri dan gaya koping (Potter \& Perry, 2005).

Penggunaan stimulus kutaneus yang benar dapat mengurangi persepsi nyeri dan membantu mengurangi ketegangan otot yang dapat menurunkan nyeri, pelebaran pembuluh darah dan memperbaiki peredaran darah di dalam jaringan tersebut, meningkatkan relaksasi fisik dan psikologis (Potter \& Perry, 2005: Kusyati, 2006).

Beberapa penelitian telah membuktikan keefektifan stimulus ini pada berbagai masalah kesehatan, seperti penelitian yang dilakukan oleh Mok \& Woo (2004) membuktikan adanya pengaruh stimulasi kutaneus slow stroke back massage terhadap penurunan kecemasan dan intensitas nyeri bahu pada lansia yang dirawat di rumah sakit dengan stroke serta perubahan positif pada denyut jantung dan tekan darah, yang mengindikasikan relaksasi pada lansia.

Penelitian Rowe \& Alfred (1999), juga membuktikan bahwa adanya efektifitas dari stimulus kutaneus slow stroke back massage pada lansia yang menderita alzaimer dalam perilaku gelisah dengan menggunakan scala rating perilaku gelisah scoring guide.

Penanganan nyeri pada dismenore dapat dilakukan dengan terapi farmakologi dan terapi nonfarmakologi, tetapi terapi farmakologi yang diberikan dalam jangka waktu lama akan berefek samping pada gastrointestinal seperti pendarahan, ulkus lambung, diare dan retensi cairan. Sehingga diharapkan perawat dan mahasiswi dapat mengaplikasikan pemberian Stimulus kutaneus slow-stroke back massage untuk mengurangi intensitas nyeri pada nyeri dismenore.

\section{KESIMPULAN}

Penelitian ini menyimpulkan :

1. Sebelum diberikan stimulus slowstroke back message (pretest) lebih dari separuh mahasiswi (75\%) mahasiswi mengalami tingkat nyeri dismenore sedang.

2. Setelah diberikan stimulus slowstroke back message (posttest) lebih dari separuh $(58,2 \%)$ mahasiswi 
mengalami tingkat nyeri dismenore ringan.

3. Stimulus slow-stroke back message dapat menurunkan skala nyeri dismenore pada mahasiswi Stikes amanah Padang.

Saran yang dapat direkomendasikan adalah:

1. Bagi responden agar dapat memanfaatkan stimulus slow-stroke back message untuk mengurangi nyeri menstruasi (dismenore) sebagai salah satu cara non farmakologi yang aman dan mudah untuk didapatkan di rumah dan juga dapat mendukung serta memfasilitasi teman dan anggota keluarga dalam memanfaatkan stimulus slow-stroke back message untuk mengurangi dismenore.

2. Bagi institusi pendidikan (sekolah) agar dapat memberikan informasi kepada mahasiswi tentang pemanfaatan stimulus slow-stroke back message sebagai salah satu pengobatan secara nonfarmakologi dalam menurunkan nyeri menstruasi (dismenore), sehingga dapat mengurangi pemakain obat analgesik bagi mahasiswi yang mengalami dismenore.

3. Bagi penelitian selanjutnya disarankan untuk dapat melakukan penelitian tentang pengaruh stimulus slow-stroke back message pada responden yang mengalami nyeri berat setiap bulannya

\section{DAFTAR PUSTAKA}

Anna. (2009). Nyeri Haid. Diakses pada tanggal 16 Februari 2011 dari http://forum.dudung.net/index.php?action= printpage; topic $=14042.0$

Asmadi (2008). Konsep dasar nyeri.

Diakses tanggal 20 September 2011 dari http//:qittun.blogspot.com/2008/9/konsepdasar-nyeri.htm.

Badziad, A. (2003). Endokrinologi dan ginekologi (edisi 2). Jakarta: Media
Aesculapius Fakultas Kedokteran

Universitas

Chattopadhyay I., Biswas K., Bandyopadhyay U. and Banerjee R.K. (2004). Turmeric and curcumin: Biological actions and medicinal applications. Current Science. 87: 44-53.

Chomaria, N. (2008). Aku sudah gede.

Jakarta : samudera

Dianawati, Ajen. (2003). Pendidikan Seks Seperti Remaja. Jakarta: Kawan Pustaka.

Ditto, Anurogo. (2008). Segala Sesuatu Tentang Nyeri Haid. Diakses pada tanggal 12 November 2010 dari http://www.kabarindonesia.com/berita.php $?$

$\dot{\bar{E}}$ ster, M. (2005). Pedoman perawat pasien. Jakarta: EGC.

Faizah, J. (2000). Pemberdayaan wanita dalam bidang kesehatan. Yogyakarta: Yayasan Essenia Medica.

Guyton A.C. and Hall J.E. (2007). Buku Ajar Fisiologi Kedokteran. Jakarta: EGC.

Harel Z. (2006). Dysmenorrhea in adolescents and young adults: etiology and management. Journal of Pediatric and Adolescent Gynecology. 19 (6), 363.

Hillard P.A.J. (2006). Dysmenorrhea. Pediatrics in review. 27, 64-71.

Holder A., Edmundson L.D., and Erogul M. (2009). Dysmenorrhea. Diakses pada tanggal 22 September 2011 dari http://emedicine.medscape.com/article/795 677-overview

Jhonson, dkk. (2005). Prosedur perawatan di rumah pedoman untuk perawat. Jakarta: EGC.

Junizar G., Sulianingsih, and Widya K.D. (2001). Pengobatan Dismenore secara Akupuntur. Cermin Dunia Kedokteran

Kozier, Barbara: Glenora; audrey berman. (2004). Fundamental nursing: concept and procedures (edition). USA: Prentice hall.

Kusyati. (2006). Keterampilan dan prosedur laboratorium keperawatan dasar. Jakarta: EGC

Mansjoer A., Triyanti K., Savitri R., Wardhani W.I. and Setiowulan W. (2005). 
Kapita Selekta Kedokteran. 3rd ed. Vol 1. Jakarta: Media Aesculapius.

Mok E \& Woo CP. (2004). The effects of slow-stroke back massage on anxiety and shoulder pain in elderly stroke patien, http://www.sciencedirect.com/science, diakses 30 September 2011.

Poter, P. A., \& Perry, A. G. (2006). Fundamental keperawatan (edisi 4). Jakarta: EGC.

Prabowo R.P. (2008). Endometriosis. In: Winkjosastro H., Saifuddin A.B., Rachimhadhi T. Ilmu Kandungan. 2nd ed. Jakarta: PT Bina Pustaka Sarwono Prawirohardjo

Priharjo. (1999). Perawatan nyeri:

pemenuhan aktivitas istirahat pasien.

Jakarta: EGC

Richard, Deyo. (2011). Pijat bagus untuk mengobati nyeri punggung. Diakses

tanggal 20 Desember 2011 dari

http://www.detik,health.htm

Riyanto. (2001). Nyeri Haid pada Remaja. Diakes pada tanggal 21 September 2011 dari

$\underline{\text { http://www.yastroki.or.id/read.php?id=190 }}$

Robert \& David. (2004). Apa yang ingin diketahui remaja tentang seks. Jakarta : Bumi Aksara.

Sastrawinata S. (2008). Gangguan pada Masa Bayi, Kanak-kanak, Pubertas, Klimakterium, dan Senium. Jakarta: PT Bina Pustaka Sarwono Prawirohardjo.

Simanjuntak, P. (2008). Gangguan Haid dan Siklusnya. In: Winkjosastro H., Saifuddin A.B., Rachimhadhi T. Ilmu Kandungan. 2nd ed. Jakarta: PT Bina Pustaka Sarwono Prawirohardjo

Smeltzer \& Bare. (2001). Buku ajar

keperawatan medikal bedah (Edisi 8, vol I). Jakarta: ECG.

Smith, R.P. (2003). Dysmenorrhea: Etiology, Diagnosis, and Therapy. Diakses pada tanggal 21 September 2011 dari http://www.omenshealthapta.org/csm2003/ 4654.pdf.
Widjanarko, Bambang. (2006). Tinjauan Terapi pada Nyeri Haid Primer. Jakarta: Majalah Kedokteran Damianus, Vol 5. 